\title{
Class specific antibody response to gonococcal infection
}

\author{
A MIETTINEN, ${ }^{*}$ KATI HAKKARAINEN, ${ }^{*}$ P GRÖNROOS, $\ddagger$ P HEINONEN, $\dagger$ \\ K TEISALA,$\dagger$ R AINE, $\ddagger \ddagger$ I SILLANTAKA, ${ }^{* *}$ K SAARENMAA, ${ }^{* *}$ M LEHTINEN, ${ }^{*}$ \\ R PUNNONEN, $+\dagger$ J PAAVONEN $\dagger$ \\ From the Departments of *Biomedical and + Clinical Sciences, University of Tampere, the Departments of \\ $\ddagger$ Clinical Microbiology, $\dagger+$ Obstetrics and Gynaecology, and $\ddagger \ddagger$ Pathology, University Central Hospital, \\ Tampere, and the **Venereal Disease Clinic, Medical Centre of the City of Tampere, Finland
}

SUMmARY An enzyme immunoassay was used to determine IgM, IgG, and IgA antibodies to gonococcal pili in 68 patients with uncomplicated gonorrhoea, 35 women with pelvic inflammatory disease, and in 115 normal controls. A clear difference in response rate in all three antibody classes between patients with gonorrhoea and healthy controls was evident. Among women with gonorrhoea, the magnitude of antibody response was higher than among men with gonorrhoea, especially in the IgM class. No major differences were found in the overall distribution of serological findings between women with uncomplicated gonorrhoea and those with gonococcal pelvic inflammatory disease. Among this last group, however, high IgM antibody levels in acute phase sera were significantly associated with the isolation of Neisseria gonorrhoeae in the upper genital tract.

Gonococcal pili are filamentous structures present on the surface of the colonial variants $\mathrm{T} 1$ and $\mathrm{T} 2$ of Neisseria gonorrhoeae: they constitute a virulence factor for the organism. Pili are considered to be specific gonococcal antigens, ${ }^{\prime}$ and several serological tests using gonococcal pili as antigen have been described, including indirect haemagglutination, ${ }^{2}$ radioimmunoassay,' and enzyme immunoassay (EIA) ${ }^{34}$ Regardless of the method used, however, the diagnostic value of total serum antibody determinations is limited by the persistence of antibody from previous infections. ${ }^{5}$ Moreover, the time course of the class specific antibody responses in uncomplicated and complicated gonorrhoea has not been clearly defined. In the present study we applied a four layer modification of the EIA for the determination of gonococcal pilus antibodies and investigated the distribution of IgM, IgG, and IgA antibodies in patients with uncomplicated gonorrhoea and patients with pelvic inflammatory disease (PID).

\section{Material and methods}

Sera were obtained from 68 patients with gonorrhoea (39 men and 29 women) attending the Venereal Disease Clinic in Tampere between February and April 1986. Gonococcal infection was diagnosed on

Accepted for publication $11 \mathrm{July} 1988$ the basis of a positive culture of $N$ gonorrhoeae from the urethra in men and from the urethra or cervix in women. None of the patients admitted a history of gonorrhoea.

Sera were also obtained from 35 women with acute PID seen consecutively at the Department of Obstetrics and Gynaecology, University Central Hospital, Tampere. All were admitted to hospital and underwent laparoscopy and endometrial biopsy. They were evaluated as previously described in detail. ${ }^{6}$ Specimens for microbial cultures were obtained from the cervix, endometrium, fallopian tubes and rectum and handled as described previously. ${ }^{7}$

Sera were obtained from 115 apparently healthy female blood donors who served as normal controls. They were not examined or questioned regarding gonorrhoea.

Strain 6650 of $N$ gonorrhoeae was used. The antigenicity of pili from this strain has been previously characterised..$^{38}$ The pili were purified by precipitation with ammonium sulphate as described by Siegel $e t$ al. ${ }^{9}$ The purity of the pilus preparation was assessed by sodium dodecyl sulphate polyacrylamide gel electrophoresis (SDS-PAGE).

EIA METHOD FOR DETERMINATION OF ANTIBODIES TO GONOCOCCAL PILUS ANTIGEN Antibodies to gonococcal pilus antigen were assayed with a four layer modification of EIA. Microtitre plates (M129A, flat bottom, Dynatech Laboratories, 
Alexandria, Virginia) were sensitised with $150 \mu \mathrm{l}$ (per well) of the pilus antigen diluted $1 / 2000(0.5 \mu \mathrm{g} / \mathrm{ml})$ in phosphate buffered saline (PBS) (pH 7.2), incubated overnight at $37^{\circ} \mathrm{C}$, and washed with PBS, pH 7.2, containing $0.5 \%$ ( $\mathrm{vol} / \mathrm{vol}$ ) Tween 20 . The samples were diluted $1 / 100$ in PBS containing $0.05 \%$ (vol/vol) Tween $20,5 \%$ (vol/vol) horse serum, and sodium chloride (final concentration, $0.5 \mathrm{M}$ ). They were then incubated in duplicate in $100 \mu \mathrm{l}$ volumes per well for 90 minutes at $37^{\circ} \mathrm{C}$. After washing heavy chain-specific anti-human immunoglobulins of rabbit origin (Dako, Copenhagen, Denmark), $100 \mu \mathrm{l}$ per well, were incubated for 45 minutes at $37^{\circ} \mathrm{C}$. The dilutions were $1 / 4000$ for anti-gamma, 1/2000 for anti-alpha, and 1/ 2000 for anti-mu. Finally, after washing, alkaline phosphatase-conjugated anti-rabbit immunoglobulins of swine origin (Orion Diagnostica, Helsinki, Finland), diluted 1/100 in the PBS diluent were added, $100 \mu \mathrm{l}$ per well, and incubated for three hours at $37^{\circ} \mathrm{C}$. After washing, $100 \mu \mathrm{l}$ (per well) of pnitrophenylphosphate substrate (Sigma, St Louis, Missouri; $1 \mathrm{mg} / \mathrm{ml}$ ) diluted in diethanolamine- $\mathrm{MgCl}_{2}$ buffer (pH 10.0) was incubated for 30 minutes at $37^{\circ} \mathrm{C}$ and the reaction stopped by the addition of $0.3 \mathrm{M}$ $\mathrm{NaOH}$. The colour reactions were recorded with a Titertek Multiscan spectrophotometer (Eflab Ltd, Helsinki, Finland). For quantitation of antibody activity, positive and negative reference sera were included in each test. Antibody levels were expressed in arbitrary units (EIA units; EIU), which were determined according to the formula:

$$
\begin{aligned}
& \text { Antibody level }_{\text {sample }}= \\
& \text { Optical density } \\
& \text { sample }
\end{aligned}
$$

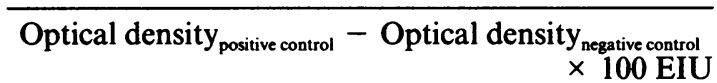

The optical density was measured at a wavelength of $405 \mathrm{~nm}$. The cut off point for clinically important antibody levels was determined as the mean of the control population $+3 \mathrm{SD}$ in IgM and IgG assays and mean $+2 \mathrm{SD}$ in IgA assays, where the overall antibody levels were substantially lower.

The $\chi^{2}$ test and Fisher's exact test, where appropriate, were used for analysis of the contingency tables and Student's $t$ test was used for comparison of the means. The sensitivity of the assay was defined as the percentage of culture positive patients who were seropositive, while specificity was defined as the percentage of normal controls who were seronegative.

\section{Results}

\section{PILUS ANTIBODIES IN PATIENTS WITH}

UNCOMPLICATED GONORRHOEA

In all immunoglobulin classes significantly higher percentages of positive sera and significantly higher mean antibody levels were observed among both men and women with current gonococcal infection than among normal controls, the difference being most striking for IgM (table, figs 1-3). With a specificity of $98 \%$ in the IgM assay, a sensitivity of $13 \%$ and $48 \%$ was reached in men and women in the acute phase, respectively. Specificity was calculated on the assumption that all positive test results obtained for normal controls were false positive results.

Among the patients initially negative for IgM antibodies, four $(12 \%)$ of the men but none of the women gave a positive IgM result when tested two weeks later. The corresponding figures for the men and women initially negative for IgG were $11(33 \%)$ and five $(24 \%)$, respectively, and for the men and women initially negative for IgA, four (11\%) and two (11\%), respectively.

The percentages of $\operatorname{IgM}$ and $\operatorname{IgA}$ positive sera were significantly higher among women than among men (table). Similarly, mean serum concentrations of gonococcal IgM, IgG, and IgA antibodies were significantly higher in women than in men (table).

Table Incidence of significant levels (EIU) of $\operatorname{IgM}, \operatorname{IgG}$, and $\operatorname{Ig} A$ antibodies to gonococcal pilus antigen in sera from 115

\begin{tabular}{|c|c|c|c|c|c|c|c|c|c|}
\hline \multirow{3}{*}{$\begin{array}{l}\text { No(\%) with } \\
\text { significant } \\
\text { titre of: }\end{array}$} & \multirow{3}{*}{$\begin{array}{l}\text { Normal } \\
\text { controls } \\
(n=115)\end{array}$} & \multirow{2}{*}{\multicolumn{4}{|c|}{$\begin{array}{l}\text { Patients with } \\
\text { uncomplicated gonorrhoea }\end{array}$}} & \multicolumn{4}{|c|}{ Women with PID } \\
\hline & & & & & & \multicolumn{4}{|c|}{$N$ gonorrhoeae } \\
\hline & & $\begin{array}{l}\text { Men } \\
(n=39)\end{array}$ & & $\begin{array}{l}\text { Women } \\
(n=29)\end{array}$ & & $\begin{array}{l}\text { Isolated } \\
(n=10)\end{array}$ & & $\begin{array}{l}\text { Not isolated } \\
(n=25)\end{array}$ & \\
\hline $\begin{array}{l}\text { IgM } \\
\text { IgG } \\
\text { IgA }\end{array}$ & $\begin{array}{l}2(2) \\
4(3) \\
2(2)\end{array}$ & $\begin{array}{l}5(13) \\
6(15) \\
3(8)\end{array}$ & $p<0.01$ & $\begin{array}{c}14(48)^{*} \\
8(28) \\
11(38) \dagger\end{array}$ & $p<0.001$ & $\begin{array}{l}5(50) \dagger \dagger \\
3(30) \\
4(40)^{* *}\end{array}$ & $\mathrm{p}<0.001$ & $\begin{array}{l}0(-) \\
1(4) \\
3(12)\end{array}$ & \\
\hline $\begin{array}{l}\text { Mean (SD) level: } \\
\text { IgM } \\
\text { IgG } \\
\text { IgA }\end{array}$ & $\begin{array}{r}10(11) \\
10(17) \\
4(16)\end{array}$ & $\begin{array}{l}20(19) \\
20(27) \\
13(12)\end{array}$ & $p<0.01$ & $\begin{array}{l}49(33)^{*} \\
43(45) \ddagger \\
34(39) \dagger\end{array}$ & $p<0.001$ & $\begin{array}{l}50(30) \dagger \dagger \\
47(32) \ddagger \ddagger \\
28(15)^{* *}\end{array}$ & $p<0.001$ & $\begin{array}{l}13(9) \\
17(22) \\
18(16)\end{array}$ & $\mathrm{p}<0.001$ \\
\hline
\end{tabular}
healthy female blood donors, 68 patients with uncomplicated gonorrhoea, and 35 patients with PID

Significance of differences between men and women with uncomplicated gonorrhoea: ${ }^{*} p<0.001 ; \nmid p<0.01 ; \ddagger p<0.05$.

Significance of differences between PID patients with and those without $N$ gonorrhoeae: $\dagger+p<0.001 ;{ }^{* *} p<0.01 ; \ddagger \ddagger p<0.05$. 


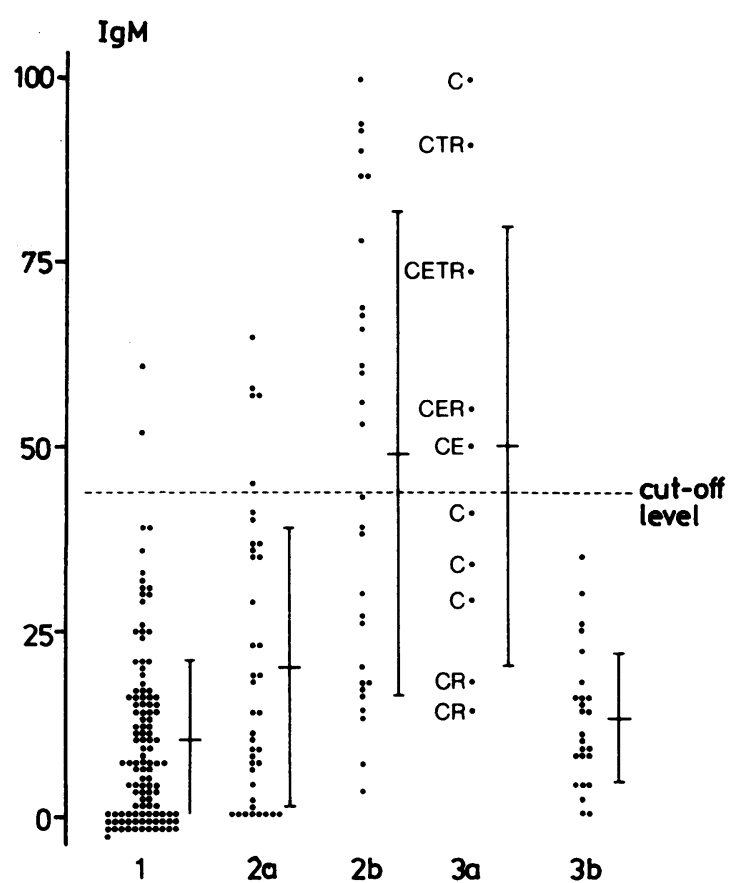

Fig 1 Distribution of IgM antibody levels to gonococcal pilus antigen in sera from (1) 115 healthy female blood donors; (2a) 39 men with uncomplicated gonorrhoea; (2b) 29 women with uncomplicated gonorrhoea; (3a) 10 women with gonococcal PID (PID); and (3b) 25 women with nongonococcal PID. The anatomical sites of the isolation of $N$ gonorrhoeae in women with $P I D$ are indicated by $C=$ cervix, $E=$ endometrium, $T=$ fallopian tubes, and $R=$ rectum. Vertical bars denote mean levels $\pm 1 S D$.

\section{PILUS ANTIBODIES IN PATIENTS WITH PID}

Of the 35 women with PID, cervical gonorrhoea was diagnosed in $10(29 \%)$. $N$ gonorrhoeae was also isolated from the fallopian tubes of one patient, from the fallopian tubes and endometrium of one patient, and from the endometrium of two patients. Six patients also harboured $N$ gonorrhoeae in the rectum.

Significantly higher percentages of positive sera as well as significantly higher mean antibody levels were observed among patients with gonococcal PID than among those with non-gonoccocal PID, the difference again being most striking for IgM (table). In contrast, no major differences were observed in the overall distribution of serological findings between women with gonococcal PID and those with uncomplicated gonococcal infection. Levels of IgM antibody were, however, related to the extent of gonococcal infection, so that all of the four patients with $N$ gonorrhoeae isolated from either fallopian tubes or endometrium, or both sites, had significant (by definition) IgM levels, compared with only one of the six patients in whom $N$ gonorrhoeae was recovered from the cervix and rectum but not from the upper genital tract $(p=0.024$, Fisher's exact test) (fig 1). Such high IgM levels were not observed among the 25 women with non-gonococcal PID nor among normal controls. A similar but less clear correlation was found for IgA levels (fig 3); the distribution of $\mathrm{IgG}$ antibody was not related to the site of isolation of $\mathrm{N}$ gonorrhoeae.

None of the patients with gonococcal PID negative for IgM antibodies in the acute phase yielded a positive result when examined two to four weeks later. In contrast, one of the seven patients initially negative for IgG antibodies, and two of the six patients initially negative for IgA antibodies, gave a positive result in the convalescent phase serum sample.

\section{Discussion}

This report describes the determination of class specific antibody response to gonococcal pili in human

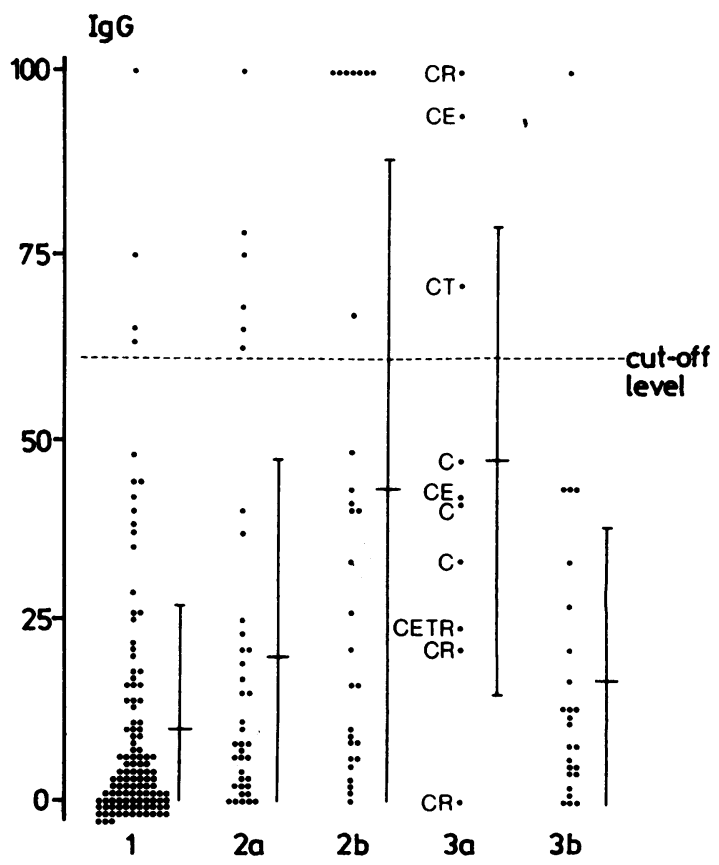

Fig 2 Distribution of IgG antibody levels to gonococcal pilus antigen in sera (1) from 115 healthy female blood donors; (2a) 39 men with uncomplicated gonorrhoea; (2b) 29 women with uncomplicated gonorrhoea; (3a) 10 women with gonococcal PID (PID); and (3b) 25 women with nongonococcal PID. The anatomic sites of the isolation of $N$ gonorrhoeae among women with PID are indicated by $C=$ cervix, $E=$ endometrium, $T=$ fallopian tubes, and $R=$ rectum. Vertical bars denote mean levels $\pm 1 S D$. 


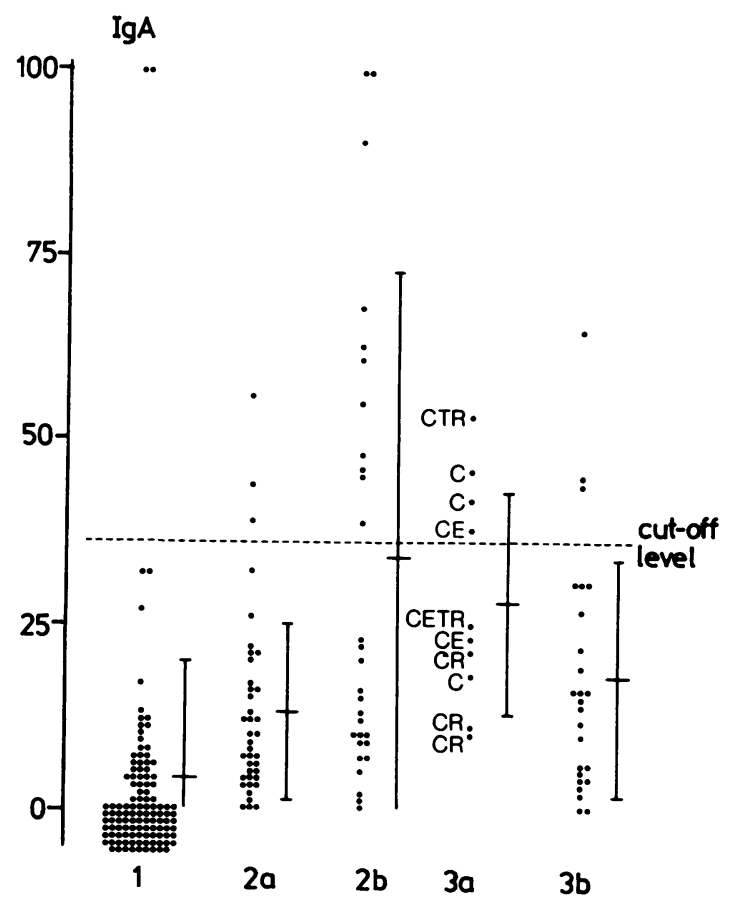

Fig 3 Distribution of $\operatorname{Ig} A$ antibody levels to gonococcal pilus antigen in sera from (1) 115 healthy female blood donors; (2a) 39 men with uncomplicated gonorrhoea; (2b) 29 women with uncomplicated gonorrhoea; (3a) 10 women with gonococcal PID (PID); and (3b) 25 women with nongonococcal PID. The anatomic sites of the isolation of $N$ gonorrhoeae among women with PID are indicated by $C=$ cervix, $E=$ endometrium, $T=$ fallopian tubes, and $R=$ rectum. Vertical bars denote mean levels $\pm 1 S D$.

sera by means of a four layer modification of EIA.

In all immunoglobulin classes significantly higher mean antibody activity and a higher percentage of positive sera were found in men and women with gonorrhoea than in controls. The determination of IgM antibodies most effectively discriminated between patients with gonorrhoea and healthy controls. A clinically important level of anti-gonococcal IgM was shown in $(13 \%)$ of infected men and in $(48-50 \%)$ of infected women in the acute phase compared with $(0-2 \%)$ of non-infected patients with PID and healthy controls. An IgM response in the early phase of gonococcal infection has also been shown to occur in patients with uncomplicated gonorrhoea by McMillan et $a l^{10}$ who used an immunofluorescence technique (IFAT) with whole cell antigen. In contrast, a predominance of IgG antibodies even early in the disease has been suggested in studies with IFAT using the heat labile surface antigens, " and with EIA using the envelope antigen of $N$ gonorrhoeae. ${ }^{12}$ It is likely that the different antigens used account for this discrepancy.

Women with gonococcal PID showed significantly higher antibody activity than women with non-gonococcal PID. Altogether, nine of the 10 patients with gonococcal PID had a clinically important level of IgM, IgG, or IgA antibodies compared with only six $(20 \%)$ of 25 patients with non-gonococcal PID. The overall percentage of seropositive cases was thus higher than that previously reported with radioimmunoassay (RIA) and indirect haemagglutination pilus antigen tests by Mårdh $e t a l,{ }^{13}$ and the same as reported with pilus RIA by Eschenbach et al. ${ }^{14}$ Moreover, unlike the 25 cases of non-gonococcal PID in this study, all women with PID and $N$ gonorrhoeae isolated from the upper genital tract had high IgM activity, suggesting that in the acute phase of the disease IgM antibody activity reflects more clearly than IgG or IgA antibody activity the extent of gonococcal infection.

It has been estimated that almost half of the women with symptomatic or asymptomatic gonorrhoea develop upper genital tract infection. ${ }^{15}$ In agreement with this, of $14(48 \%)$ of 29 women in the current study, who had $N$ gonorrhoeae in the cervix but did not have upper genital tract symptoms or signs, showed as high IgM antibody levels as did those patients with confirmed PID in whom $N$ gonorrhoeae was found in the upper genital tract. The high antibody activity might reflect a subclinical PID in such cases. Confirmation of this calls for laparoscopy and endometrial sampling among asymptomatic women with positive cervical cultures for $N$ gonorrhoeae.

The gonococcal pili used here were from a single strain (6650 of $N$ gonorrhoeae). The failure in this study to show an antibody response in half of uncomplicated gonococcal infections could have been due partly to the antigenic heterogeneity of the gonococcal pili, ${ }^{8}$ but also to the testing of patients with infections of varying severity. Because of the relatively low overall response rate, the test obviously cannot be regarded as an effective diagnostic tool in its own right in gonorrhoea. The observed sex difference in antibody response and the uniform IgM response among patients with PID in whom $N$ gonorrhoeae was detected in the upper genital tract suggest, however, that the determination of antibody response can be used as an indicator of the extent of gonococcal infection.

This study was supported in part by a grant (7939/304/ 83) from the Academy of Finland.

We thank Drs Karin Reimann and Inga Lind, Statens Seruminstitut, Neisseria Department, Copenhagen, Denmark, for providing the $N$ gonorrhoeae strain 6650. 
References

1 Buchanan TM, Swanson J, Holmes KK, Kraus SJ, Gotschlich EC. Quantitative determination of antibody to gonococcal pili. Changes in antibody levels with gonococcal infection. J Clin Invest 1973;52:2896-909.

2 Reimann K, Lind I, Andersen KE. An indirect haemagglutination test for demonstration of gonococcal antibodies using gonococcal pili as antigen. II. Serological investigation of patients attending a dermato-venereological out-patients clinic in Copenhagen. Acta Pathol Microbiol Scand (Sect C) 1980;88:155-62.

3 Oranje AP, Reimann K, de Roo A. Schouten HJA, Stolz E, Michel MF. Enzyme-linked immunosorbent assay for detecting gonococcal antibodies using two antigenically different gonococcal pili as antigen. British Journal of Venereal Disease 1983;59: 89-91.

4 Young H, Low AC. Serological diagnosis of gonorrhoea: detection of antibodies to gonococcal pili by enzyme-linked immunosorbent assay. Med Lab Sci 1918;38:41-7.

5 Holmes KK, Buchanan TM, Adam JL, Eschenbach DA. Is serology useful in gonorrhoea? A critical analysis of factors influencing serodiagnosis. In: Brooks GF, Gotschlich EC, Holmes KK, Sawyer WD, Young FE, eds. Immunobiology of Neisseria gonorrheae. Washington, DC: American Society for Microbiology, 1978:370-6.

6 Paavonen J, Teisala K, Heinonen PK, et al. Microbiological and histopathological findings in acute pelvic inflammatory disease. Br J Obstet Gynaecol 1987;94:454-60.

7 Heinonen PK, Teisala K, Aine R, et al. Anatomic sites of upper genital tract infection. Obstet Gynaecol 1985;66:384-90.

8 Reimann K, Oranje AP, Michel MF. Demonstration of antigenic heterogeneity of Neisseria gonorrhoeae pili antigens using human sera in the test system. Acta Pathol Microbiol Scand (Sect C) 1982;90:47-52.

9 Siegel M, Olsen D, Critchlow C, Buchanan TM. Gonococcal pili: safety and immunogenicity in humans and antibody function in vitro. J Infect Dis 1982;145:300-10.

10 McMillan A, McNeillage G, Young H, Bain SR. Serum immunoglobulin response in uncomplicated gonorrheae. British Journal of Venereal Disease 1979;55:5-9.

11 Cohen IR, Kellogg DS, Norins LC. Serum antibody response in experimental gonorrhea. Immunoglobulins G, A and M. British Journal of Venereal Disease 1969;45:325-7.

12 Ison CA, Glynn AA. Classes of antibodies in acute gonorrhoea. Lancet 1979; i:1165-8.

13 Mårdh P-A, Buchanan T, Christiansen P, Danielsson D, Lind I, Reimann K. Comparison of four serological tests for detection of gonococcal antibodies in patients with complicated gonococcal infections. In: Brooks GF, Gotschlich EC, Holmes KK, Sawyer WD, Young FE, eds. Immunobiology of Neisseria gonorrheae. Washington, DC: American Society for Microbiology, 1978:377-81.

14 Eschenbach DA, Buchanan TM, Pollock HM, et al. Polymicrobial etiology of acute pelvic inflammatory disease. $N$ Engl $J$ Med 1975;293:166-71.

15 Platt R, Rice PA, McCormack WM. Risk of acquiring gonorrhea and prevalence of abnormal adnexal findings among women recently exposed to gonorrhea. JAMA 1983;250:3205-9.

Requests for reprints to: Dr Ari Miettinen, Department of Biomedical Sciences, University of Tampere, Box 607, SF-33101 Tampere, Finland. 